\title{
CONFIANÇA, CONTROLES E RISCOS EM RELACIONAMENTOS INTERORGANIZACIONAIS NO ÂMBITO DE CADEIAS DE SUPRIMENTOS
}

\author{
TRUST, CONTROL AND RISKS IN \\ INTERORGANIZATIONAL RELATIONSHIPS \\ WITHIN SUPPLY CHAINS
}

\author{
Recebido: $10 / 03 / 2015$ \\ Aceito: 17/05/2015 \\ Diego Antonio Bittencourt Marconatto ${ }^{1}$ \\ Vania Estivalete ${ }^{2}$ \\ Eugenio Avila Pedrozo 3
}

\section{RESUMO}

As pesquisas realizadas no âmbito das cadeias de suprimentos não têm considerado de forma sistematizada a inter-relação existente entre a confiança, os controles e riscos interorganizacionais. Assim, o presente trabalho tem o objetivo de responder a seguinte questão de pesquisa: como a confiança, os controles e os riscos interorganizacionais se afetam mutuamente no âmbito das cadeias de suprimentos? Para tanto, o framework teórico de Das e Teng (2001) é operacionalizado em uma das maiores cadeias de suprimentos do Brasil. Através das quinze entrevistas e da pesquisa documental realizadas, emergiram oito proposições principais. Em conjunto, essas proposições permitem observar que (a) a análise conjunta da confiança, do controle e do risco oferece uma capacidade de compreensão contextual maior do que análises individuais desses constructos e que (b) os relacionamentos estabelecidos entre confiança, controles e riscos interorganizacionais são complexos. Dessa forma, perspectivas lineares de investigação não são suficientes para fazer frente à natureza das inter-relações mantidas entre esses três constructos. As implicações gerenciais concentram-se na capacidade analítica que o framework adaptado oferece para auxiliar na definição de tipos e extensão de controles a serem negociados e na sistematização da verificação dos riscos com maior potencial de dano ao negócio.

Palavras-chave: Confiança, controle, riscos, relacionamentos interorganizacionais, cadeia de suprimentos.

\footnotetext{
1 Possui graduação em Administração: Habilitação em Comércio Exterior pela Faculdade Metodista de Santa Maria - FAMES. Mestrado em Administração pela Universidade Federal de Santa Maria - UFSM. Doutorado em Administração pela Universidade Federal do Rio Grande do Sul. Pós-Doutorado pela École des Hautes Études Commerciales de Montréal - HEC Montréal. Atualmente é professor adjunto da Universidade Federal de Santa Maria. Santa Maria, Rio Grande do Sul, Brasil. E-mail: diego.marconatto@ufsm.br

2 Possui graduação em Administração, especialização em Gerência da Produção, mestrado em Engenharia de Produção pela Universidade Federal de Santa Maria - UFSM. Doutorado em Agronegócios pela Universidade Federal do Rio Grande do Su - UFRGS. Pós -Doutorado pela Universidade de Lisboa - UL. Atualmente é professora adjunta da Universidade Federal de Santa Maria. Santa Maria, Rio Grande do Sul, Brasil. E-mail: vaniaestivalete@ufsm.br

3 Possui graduação em Engenharia Agronômica pela Universidade Federal de Santa Maria - UFSM. Graduação em Administração de Empresas, Ciência Contábeis e especialização em Custos e Auditoria pela Universidade Regional Integrada do Alto Uruguai e das Missões - URI. Especialização em Economia Rural pela Universidade Regional do Noroeste do Estado do Rio Grande do Sul - UNIJUI. Mestrado em Administração pela Universidade Federal do Rio Grande do Sul - UFRGS. Doutorado em Genie Industrielle pela Institut National Polytechnique de Lorraine. Atualmente é professor associado da Universidade Federal do Rio Grande do Sul. Porto Alegre, Rio Grande do Sul, Brasil. E - mail: eapedrozo@ea.ufrgs.br
} 


\begin{abstract}
The research efforts involving supply chains have not been investigating systematically the existent interrelations between interorganizacional trust, control and risks. Hence, this work aims to answer the following research question: How do interorganizacional trust, controls and risks affect each other in the context of supply chains? We perform it by employing the Das and Teng's (2001) research framework into one of the largest Brazilian supply chains. Eight key propositions emerged from fifteen interviews and documental investigation. Altogether, such propositions allow to observe that (a) the joint analysis of interorganizacional trust, controls and risk provides a higher level of understanding of such elements in comparison with their individual analysis; (b) the various relationships between interorganizacional trust, controls and risks are complex, so linear research approaches are not adequate to comprehend their reality. The managerial implications of this study are the analytic capacity offered by the research framework for defining the types and extension of controls to be negotiated and for systemizing the largest risks to the business.
\end{abstract}

Keywords: Trust, control, risks, interorganizational relationships, supply chains.

\title{
1 INTRODUÇÃO
}

As cadeias de suprimentos (supply chains) são fundamentais para as economias modernas, afetando profundamente a vida das populações em geral nos mais diversos aspectos (NEW, 1997) ${ }^{4}$. Seu princípio básico de sustentação é o planejamento interorganizacional, baseado no compartilhamento de informações e na confiança entre os parceiros da cadeia (CHU; FANG, 2006).

A confiança é, de fato, um dos elementos mais importantes para a integração e o sucesso das cadeias de suprimentos (Chu; Fang, 2006; Sahay, 2003). Entretanto, embora a confiança reduza incertezas, ela produz riscos (BACHMANN, 1998), havendo, então, a necessidade inerente de lidar com esse risco. Tal constatação leva a outro arcabouço teórico importante: o controle, necessário como complementar ou substituto da confiança. Confiança e controle estão intimamente imbricados e têm, em conjunto, a função primeira de aumentar a previsibilidade das ações dos atores sociais e, logo, de diminuir os riscos de geração de perdas nas transações realizadas (MÖLLERING, 2005).

Assim sendo, analisar a confiança e o controle de modo isolado tende a limitar o entendimento mais aprofundado desses constructos. Logo, autores como Larson e Rogers (1998) e Das e Teng (2001) propõem uma visão conjunta desses fatores, existindo ainda o risco como um fator inerente a ambos. Para Das e Teng, "não há um terceiro determinante de importância comparável - à confiança e ao controle - no que tange ao risco e à incerteza relacionais" (2001, p. 253). Isso mostra que uma capabilidade relacional sustentada sobre a confiança exige uma abordagem conjunta de controles e riscos. Mesmo assim, não se observa a articulação sistemática desses três constructos, o que deixa lacunas no entendimento teórico do relacionamento entre eles e especialmente quanto à própria confiança (INKPEN; CURRAL, 2004). Entende-se que avançar sobre essa temática é importante devido ao seu impacto nos relacionamentos interorganizacionais no contexto das cadeias de suprimentos (SAHAY, 2003).

Assim, dada à relevância das cadeias de suprimentos (SAHAY; 2003; NEW, 1997), da confiança (MCEVILY et al., 2003; BARNEY; HANSEN, 1994; DAS; TENG, 2001), dos controles e dos riscos (BIJLSMA-FRANKEMA; COSTA, 2005; DAS; TENG, 2001; BACHMANN, 1999; MÖLLERING, 2005) e à existência das lacunas teóricas mencionadas no presente artigo, busca-se responder a seguinte questão de pesquisa: como a confiança, os controles e os riscos se afetam mutuamente no âmbito de cadeias de suprimentos?

4 New (1997) entende que o sistema internacional de criação de necessidades de consumo através da mídia propagandista de massa viabiliza-se principalmente devido às cadeias de suprimentos permitirem um fluxo cada vez mais rápido de inovações a preços viáveis. 
Como a finalidade de responder essa questão, propõem-se três objetivos secundários: (1) caracterizar as díades da cadeia de suprimentos da empresa focal deste estudo; (2) investigar a confiança, os controles e os riscos interorganizacionais nas díades propostas para análise; e (3) identificar diferenças e similaridades relacionais evidenciadas quanto aos diversos tipos de confiança, controles e riscos percebidos pelas empresas pesquisadas na cadeia de suprimentos da empresa focal. $O$ atendimento desses objetivos permite o atingimento do objetivo principal da pesquisa: compreender as influências geradas pelos diferentes tipos de confiança, controles e riscos interorganizacionais percebidos, uns sobre os outros, no âmbito de uma cadeia de suprimentos.

Frente a esse conjunto de objetivos, foi empreendida uma pesquisa exploratória de natureza qualitativa em uma das maiores cadeias de suprimentos do Brasil, direcionada à produção de bebidas não alcoólicas, nos anos de 2008 e 2009.

O presente trabalho estrutura-se da seguinte forma: primeiro, será abordado o constructo da confiança interorganizacional; em seguida, são expostos os controles, os riscos e a relação de ambos com a confiança; após, todos os conceitos são imbricados em um framework único, para, posteriormente, os resultados serem apresentados com sua subsequente discussão; por fim, apresentam-se as conclusões finais deste trabalho.

\section{A CONFIANÇA NO ÂMBITO DOS RELACIONAMENTOS INTERORGANIZACIONAIS}

Por muitos anos, o construto da confiança tem captado interesse de várias áreas de estudo (SVENSSON, 2001). Morgan e Hunt (1994), por exemplo, denominaram-na de principal determinante no comprometimento de um relacionamento. Tais autores consideram a confiança um elemento-chave pelo fato de encorajar os negociadores a: diminuírem a incerteza na tomada de decisão, a resistirem às alternativas atrativas de curto prazo (oportunismo) em prol dos benefícios de longo prazo e a visualizarem ações de alto risco como sendo viáveis, devido à crença de que seus parceiros não agirão de modo oportunista (diminuição do risco percebido). Barney e Hansen (1994) entendem a confiança como sendo a mútua crença de que nenhuma das partes de um relacionamento explorará as vulnerabilidades da outra parte ${ }^{5}$. Neste e em outros conceitos de confiança, verifica-se explícita ou implicitamente a noção de vulnerabilidade, risco e incerteza relacional gerada pela racionalidade limitada (SIMON, 1976): já que uma parte não tem certeza de como a outra parte se comportará em relação à determinada situação, há a necessidade de confiar para o estabelecimento da relação, sendo nesta relação de confiança em que reside o risco.

A literatura aborda vários tipos de confiança, destacando-se quatro: confiança forte -pura, confiança média-forte, confiança fraca e confiança baseada em competência (DAS; TENG, 2001; BARNEY; HANSEN, 1994). A Figura 1, a seguir, resume os principais aspectos de cada tipo.

\begin{tabular}{|c|l|}
\hline $\begin{array}{c}\text { Tipo de } \\
\text { confiança }\end{array}$ & \multicolumn{1}{c|}{ Características } \\
\hline $\begin{array}{c}\text { Confiança } \\
\text { forte-pura }\end{array}$ & $\begin{array}{l}\text { Diz respeito às boas intenções, à fé e à integridade; é bastante diversa do conceito de } \\
\text { confiança calculativa }{ }^{1} \text {, que tem ênfase puramente econômica. }\end{array}$ \\
\hline $\begin{array}{c}\text { Confiança } \\
\text { média-forte }\end{array}$ & $\begin{array}{l}\text { Emerge quando a relação é sustentada por vários dispositivos de coordenação (controles } \\
\text { formais configurados de diversas maneiras). Esse modelo de confiança enfatiza o papel da } \\
\text { racionalidade e da confiança calculada na tomada de decisão. }\end{array}$ \\
\hline $\begin{array}{c}\text { Confiança } \\
\text { fraca }\end{array}$ & $\begin{array}{l}\text { Baseia-se no pressuposto de que uma parte não explorará as vulnerabilidades da outra pelo fato, } \\
\text { simplesmente, de não existirem vulnerabilidades significativas a explorar na troca específica. }\end{array}$ \\
\hline
\end{tabular}

5 Para a verificação dos vários conceitos de confiança aplicados a cadeias de suprimentos, ver Sahay (2003). 


\begin{tabular}{|c|l|}
\hline $\begin{array}{c}\text { Tipo de } \\
\text { confiança }\end{array}$ & \multicolumn{1}{c|}{ Características } \\
\hline $\begin{array}{c}\text { Confiança } \\
\text { baseada em } \\
\text { competência }\end{array}$ & $\begin{array}{l}\text { Está estruturada sobre a percepção da capacidade técnica da outra parte em cumprir com } \\
\text { suas obrigações relacionais. }\end{array}$ \\
\hline
\end{tabular}

Figura 1 - Principais tipos de confiança

Fonte: Das e Teng (2001) e Barney e Hansen (1994)

Como a confiança age sobre as vulnerabilidades relacionais, tendendo a diminuí-las, alguns autores a investigam como se operasse em conjunto com diversos controles, isto é, como se a confiança e os controles se complementassem ou se substituíssem (BIJLSMA-FRANKEMA, 2005; MÖLLERING et al., 2001). Tais autores também tratam esses constructos juntamente com a percepção de risco, inerente, em menor ou maior grau, aos relacionamentos interorganizacionais. Como a confiança, o controle e o risco trazem efeitos diversos uns sobre os outros (INKPEN; CURRALL, 2004), deve-se, também, compreender a dinâmica dos controles e dos riscos interorganizacionais.

\section{OS CONTROLES E OS RISCOS EM RELACIONAMENTOS INTERORGANIZACIONAIS}

Das e Teng (1998, p. 493) conceituam mecanismos de controle como "arranjos organizacionais projetados para determinar e influenciar o que os membros organizacionais farão, enquanto que nível de controle é o grau em que determinado comportamento é garantido". Logo, "bons mecanismos de controle significam que uma pessoa informada pode ficar razoavelmente confiante que não ocorrerão grandes e desagradáveis surpresas" (DAS; TENG, 2001, p. 493). Tais surpresas normalmente são a conversão dos riscos negativos em realidade. Isso coloca em evidência a relevância dos riscos no âmbito dos controles e também da confiança.

Quanto ao risco, este pode ser conceituado como a possibilidade de obtenção de resultados (outputs) negativos (BACHMANN, 1999). Riscos são muito importantes no entendimento da relação controle-confiança, pois tanto os controles quanto a confiança têm dentre suas principais metas a mitigação, cada um a seu modo, da percepção da possibilidade de ocorrência de resultados negativos, que nada mais é do que o risco (DAS; TENG, 2001). O risco também é vital na relação confiança-controle, porque as empresas que estabelecem transações têm, cada qual, uma percepção do nível máximo de risco a que podem se submeter, além do qual a aliança se torna demasiada perigosa (BACHMANN, 1999). Assim, é natural supor que diferentes percepções de risco demandam diferentes níveis e tipos de controles e confiança, bem como, quanto maior a sensibilidade ao risco, maiores precisam ser a confiança e os controles, sendo o inverso igualmente lógico. Os controles, funcionando como dispositivos de gerenciamento de riscos, são institucionalizados por meio de especificações contratuais, arranjos gerenciais, e outros mecanismos mais informais (DAS; TENG, 2001). A Figura 2, exposta a seguir, resume os principais tipos de controles e riscos existentes, assim como suas características essenciais.

\begin{tabular}{|l|l|}
\hline \multicolumn{1}{|c|}{$\begin{array}{c}\text { Riscose } \\
\text { controles }\end{array}$} & \multicolumn{1}{c|}{ Características } \\
\hline $\begin{array}{l}\text { Risco relacional/ } \\
\text { moral }\end{array}$ & $\begin{array}{l}\text { É a probabilidade de incursão de uma das partes em comportamentos oportunistas } \\
\text { que possam gerar perdas assimétricas entre os parceiros. }\end{array}$ \\
\hline $\begin{array}{l}\text { Risco de perfor- } \\
\text { mance }\end{array}$ & $\begin{array}{l}\text { É a probabilidade de ineficácia da parceria por questões estruturais externas ou por } \\
\text { incompetência das partes em cumprir com suas respectivas obrigações relacionais. }\end{array}$ \\
\hline
\end{tabular}




\begin{tabular}{|c|c|c|c|}
\hline $\begin{array}{l}\text { Riscos e } \\
\text { controles }\end{array}$ & \multicolumn{3}{|c|}{ Características } \\
\hline $\begin{array}{l}\text { Risco de investi- } \\
\text { mentos específi- } \\
\text { cos }\end{array}$ & \multicolumn{3}{|c|}{$\begin{array}{l}\text { Existe quando uma das partes efetua investimentos de grande porte, assimétricos e } \\
\text { específicos (logo, de difícil mobilidade para outros clientes) para atendimento à outra } \\
\text { parte. Ou seja, essa vulnerabilidade existe quando se configura uma relação de depen- } \\
\text { dência de uma organização em relação à(s) outra(s). }\end{array}$} \\
\hline $\begin{array}{l}\text { Risco de seleção } \\
\text { adversa }\end{array}$ & \multicolumn{3}{|c|}{$\begin{array}{l}\text { Existe quando uma parte percebe como excessivamente custoso o aferimento ade- } \\
\text { quado do valor do objeto oferecido pela outra parte, existindo o risco de supervalo- } \\
\text { rizar o objeto a ser recebido, incorrendo-se em uma troca desproporcional e/ou des- } \\
\text { vantajosa. }\end{array}$} \\
\hline \multirow{2}{*}{$\begin{array}{l}\text { Controles for- } \\
\text { mais (baseados } \\
\text { em medidas) }\end{array}$} & \multirow{2}{*}{$\begin{array}{l}\text { Enfatiza o estabelecimento e } \\
\text { a utilização de regras formais, } \\
\text { procedimentos e políticas } \\
\text { para monitorar e recompen- } \\
\text { sar performances desejadas. }\end{array}$} & $\begin{array}{l}\text { Controles com- } \\
\text { portamentais }\end{array}$ & $\begin{array}{l}\text { Mensuração ocorre sobre os com- } \\
\text { portamentos em si e não sobre os } \\
\text { outputs finais - normalmente de- } \\
\text { vido ao fato de que nestes casos a } \\
\text { mensuração dos outputs ou não é } \\
\text { possível ou é demasiada imprecisa. }\end{array}$ \\
\hline & & $\begin{array}{l}\text { Controles de ou- } \\
\text { tput }\end{array}$ & $\begin{array}{l}\text { Mensuração de seus resultados } \\
\text { (ou controle de outputs) serve para } \\
\text { avaliar de modo seguro e acurado o } \\
\text { desempenho dos membros. }\end{array}$ \\
\hline $\begin{array}{l}\text { Controles infor- } \\
\text { mais (baseados } \\
\text { em valores) }\end{array}$ & \multicolumn{3}{|c|}{$\begin{array}{l}\text { Baseia-se no estabelecimento de normas e valores, na cultura e na internalização de } \\
\text { objetivos para encorajar comportamentos e resultados desejáveis. Esse tipo de con- } \\
\text { trole é também chamado de controle normativo, social ou informal. }\end{array}$} \\
\hline
\end{tabular}

Figura 2 - Principais tipos de riscos e controles

Fonte: Das e Teng (2001), Barney e Hansen (1994) e Ouchi e Maguire (1975)

Os controles formais tendem a serem mais previsíveis e regulares e envolvem a transferência de informações explícitas, as quais são codificadas em regras e procedimentos (BIJLSMAFRANKEMA; COSTA, 2005). Já os controles sociais são mais incertos, ambíguos e imbricados organizacionalmente e têm como objetivo reduzir a incongruência de objetivos entre os membros da organização ou entre os parceiros de um relacionamento interorganizacional (DAS;TENG, 1998). Controles informais, ao contrário dos formais, não determinam comportamentos nem resultados específicos antes do início de sua instauração - ex ante -, sendo seu processo de definição de objetivos descentralizado, o que explica por que os controles sociais são particularmente apropriados para utilização em circunstâncias ambíguas (MCEVILY et al., 2003; DAS; TENG, 2001).

Esse embasamento teórico acerca dos diversos tipos de confiança, controles e riscos serve de alicerce para a construção de um framework de análise, tendo-se como base o modelo teórico desenvolvido por Das e Teng (2001). Foram integrados a esse modelo os tipos de confiança e riscos de Barney e Hansen (1994) que não fazem parte de sua estrutura original. As semelhanças existentes - explicitadas no corpo teórico deste artigo - entre as variáveis originais de Das e Teng (2001) e as outras que foram adicionadas no modelo motivaram o agrupamento de algumas variáveis: confiança pura e confiança forte (doravante chamada de confiança forte/ pura); e risco relacional e risco moral (sendo tratado como risco relacional/moral). Assim sendo, a Figura 3, a seguir, mostra o framework de Das e Teng (2001) adaptado. 


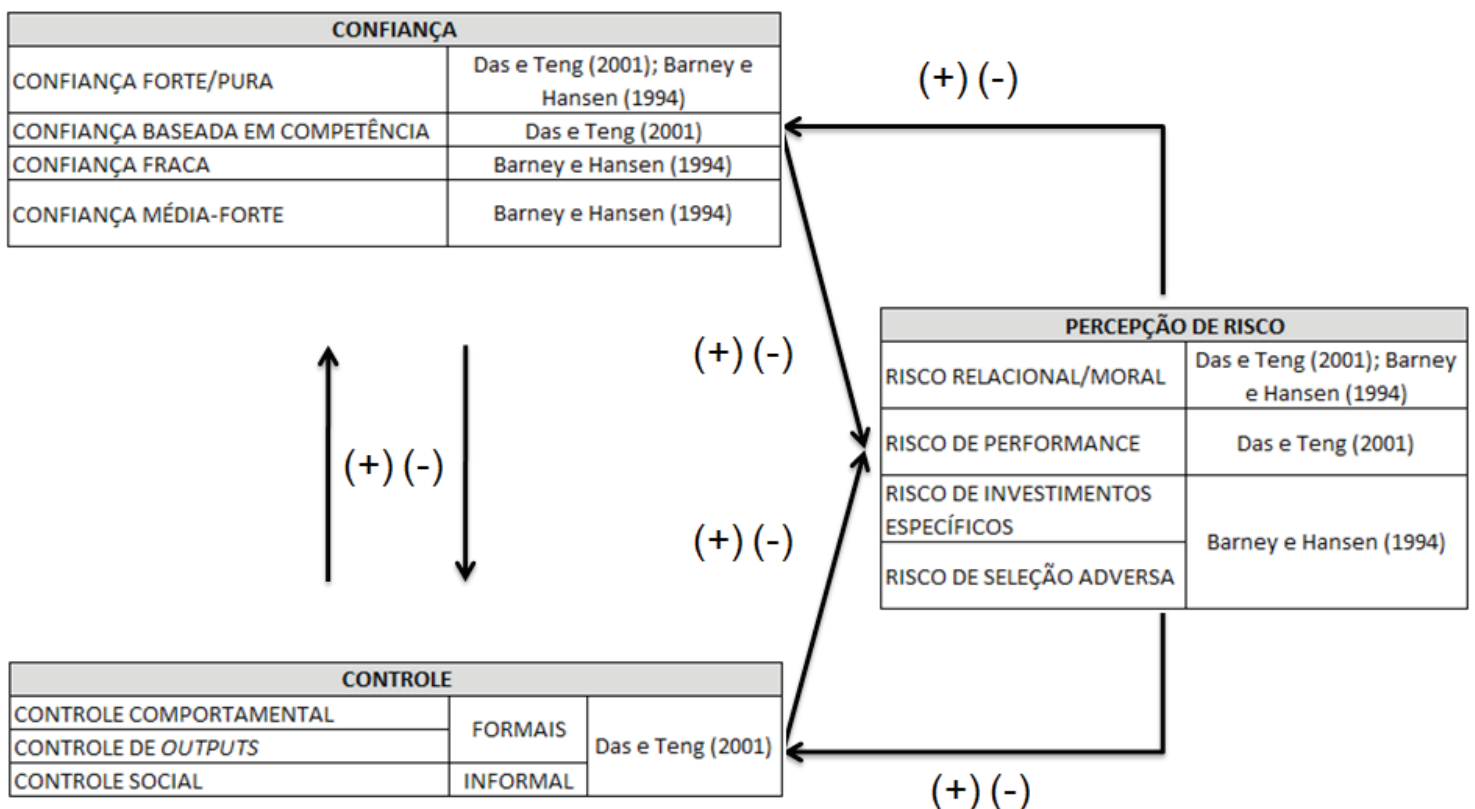

Figura 3 - Modelo conceitual de pesquisa da influência mútua dos tipos de confiança, controles e riscos percebidos em relacionamentos no ambiente de cadeias de suprimentos

Fonte: elaborado com base em Das e Teng (2001) e Barney e Hansen (1994)

Conforme mostra o modelo de pesquisa, os diferentes tipos de riscos, controles e confiança afetam-se mutuamente. Segundo alguns autores (INKPEN; CURRAL, 2004; DAS; TENG, 2001), existem pontos fundamentais a considerar nesse conjunto de inter-relações, caracterizados por efeitos específicos quando ocorre a relação entre algumas das variáveis mencionadas (a Figura 4 resume essas proposições).

\begin{tabular}{|l|}
\hline Relação \\
\hline Risco relacional/moral $\rightarrow$ confiança \\
pura, controles comportamentais e \\
sociais
\end{tabular}

Risco de performance $\rightarrow$ confiança baseada em competência e controles sociais e de output

Controles formais $\rightarrow$ confiança pura e baseada em competência

Controles informais $\rightarrow$ confiança pura e baseada em competência

\section{Efeitos previstos}

Quanto menor a aceitação do risco relacional percebido por parte de $A$, maiores deverão ser os níveis de confiança pura e de controles comportamentais e sociais sobre $B$.

Quanto menor a aceitação do risco de performance percebido por A, maior a necessidade de confiança baseada em competência, de controles sociais e de outputs sobre $B$.

Controles formais (de outputs) tendem a focalizar os esforços dos parceiros no curto prazo. Controles formais podem ser percebidos como um sinal de que os parceiros não são suficientemente competentes para executar os processos a seu próprio modo, de forma que a confiança baseada em competência também é prejudicada. Isso dificulta a busca de objetivos de longo prazo

Controles informais (sociais) não definem comportamentos e metas a priori, ensejando maior liberdade de ação. Como essa liberdade aumenta a exposição do parceiro que a cede, os controles sociais tendem a aumentar a confiança pura e a confiança baseada em competência.

\section{Autores}

Das e Teng (2001) 


\begin{tabular}{|c|c|c|}
\hline Relação & Efeitos previstos & Autores \\
\hline Controles formais $\rightarrow$ confiança pura & $\begin{array}{l}\text { A implantação de mecanismos formais de controles } \\
\text { por A em B diminui a confiança pura ou baseada em } \\
\text { competência em B, porque tais controles fornecem } \\
\text { explicações alternativas para seu comportamento: } \\
\text { sua motivação está mais no evitar a possível sanção } \\
\text { pelo desvio cometido do que em sua integridade in- } \\
\text { trínseca. }\end{array}$ & $\begin{array}{c}\text { Inkpen e } \\
\text { Curral } \\
\text { (2004), } \\
\text { Sitkin } \\
\text { e Roth } \\
\text { (1993) }\end{array}$ \\
\hline $\begin{array}{l}\text { Confiança pura e baseada em com- } \\
\text { petência } \rightarrow \text { controles formais e in- } \\
\text { formais }\end{array}$ & $\begin{array}{l}\text { Quanto maior o nível inicial (pré-relacionamento) de } \\
\text { confiança entre os parceiros, menor o custo inicial de } \\
\text { monitoramento e controle da parceria e maior a pro- } \\
\text { pensão e confiança na utilização dos controles sociais. } \\
\text { Controles sociais e formais funcionam melhor onde } \\
\text { há altos níveis de confiança, devido a esta diminuir } \\
\text { os níveis de resistência no uso dos controles. Logo, } \\
\text { a confiança pura e a confiança baseada em compe- } \\
\text { tência aumentam a efetividade de todos os tipos de } \\
\text { controles em uma parceria. }\end{array}$ & $\begin{array}{c}\text { Inkpen } \\
\text { e Curral } \\
\text { (2004), } \\
\text { Das e } \\
\text { Teng } \\
\text { (2001) }\end{array}$ \\
\hline
\end{tabular}

Figura 4 - Principais proposições das relações mútuas entre confiança, controles e riscos

Fonte: Das e Teng (2001), Barney e Hansen (1994) e Ouchi e Maguire (1975)

O capítulo seguinte discorre sobre como esse modelo conceitual, somado aos outros elementos da fundamentação teórica, foi utilizado na operacionalização desta pesquisa, descrevendo, também, as díades investigadas, suas organizações formadoras e outros procedimentos adotados.

\section{PROCEDIMENTOS METODOLÓGICOS}

Conforme mencionado, este trabalho compreende parte de uma pesquisa exploratória, de caráter qualitativo, que analisa três conjuntos de relacionamentos interorganizacionais - os quais somam seis empresas - que experimentaram evoluções distintas (ver Figura 5) no que diz respeito à confiança, aos controles e aos riscos. As seis empresas selecionadas participam diretamente de uma das maiores cadeias de suprimentos do Brasil, seja em termos de empregos diretos e indiretos ou em termos de faturamento bruto total (em 2008, o seu faturamento bruto chegou a aproximadamente 13 bilhões de reais). 


\begin{tabular}{|c|c|c|c|c|c|}
\hline \multirow{7}{*}{ 岀 } & Fundação & Década de 1970 & \multirow{7}{*}{ 岕 } & Fundação & Década de 1940 \\
\hline & Funcionários ( $\approx)$ & 600 & & Funcionários ( $\approx$ ) & 3.000 \\
\hline & Localização & Região sul & & Localização & Região centro-oeste \\
\hline & Clientes $(\approx)$ & 16.500 & & Clientes $(\approx)$ & 120.000 \\
\hline & Fat. Br./ano ( $\approx)$ & R\$300 milhões & & Fat. Br./ano $(\approx)$ & R\$1 bilhão \\
\hline & \multirow[t]{2}{*}{$\begin{array}{l}\text { Outras Informa- } \\
\text { ções }\end{array}$} & $\begin{array}{l}\text { Além dos refrigerantes de fa- } \\
\text { bricação própria, a EF também } \\
\text { revende uma série de outras } \\
\text { bebidas fabricadas por outras } \\
\text { empresas constituintes da mar- } \\
\text { ca global (a qual é detida pela } \\
\text { casa matriz) }\end{array}$ & & \multirow[t]{2}{*}{$\begin{array}{l}\text { Outras Informa- } \\
\text { ções }\end{array}$} & \multirow[t]{2}{*}{$\begin{array}{c}\text { O GF2 é um dos } 17 \text { GFs } \\
\text { da casa matriz atuantes } \\
\text { no Brasil }\end{array}$} \\
\hline & & $\begin{array}{l}\text { A EF é um dos } 17 \text { GFs da casa } \\
\text { matriz atuantes no Brasil }\end{array}$ & & & \\
\hline \multirow{6}{*}{ 岀 } & Fundação & Década de 1940 & \multirow{6}{*}{ 岁 } & Fundação & $\begin{array}{l}\text { GF1: déc.1950; AF: } \\
\text { déc.1980 }\end{array}$ \\
\hline & Funcionários ( $\approx)$ & 7.000 (em todo o Brasil) & & Funcionários ( $\approx)$ & GF1: 2.600; AF: 30 \\
\hline & Localização & Região sul & & Localização & $\begin{array}{l}\text { GF1: sul; AF: centro-o- } \\
\text { este }\end{array}$ \\
\hline & Fat. Br./ano ( $\approx)$ & R\$900 milhões & & Fat. Br./ano $(\approx)$ & GF1: R\$1 bilhão \\
\hline & \multirow[b]{2}{*}{$\begin{array}{l}\text { Outras Informa- } \\
\text { ções }\end{array}$} & $\begin{array}{l}\text { Em 2007, esta empresa foi ad- } \\
\text { quirida por uma empresa de } \\
\text { logística holandesa. }\end{array}$ & & & \\
\hline & & $\begin{array}{l}\text { Atividade principal: transporte } \\
\text { de encomendas e materiais, } \\
\text { desde documentos até grandes } \\
\text { volumes de matérias-primas e } \\
\text { insumos produtivos }\end{array}$ & & $\begin{array}{l}\text { Outras Informa- } \\
\text { ções }\end{array}$ & $\begin{array}{c}\text { da casa matriz atuantes } \\
\text { no Brasil }\end{array}$ \\
\hline \multirow{5}{*}{$\sum_{i}^{-1}$} & Fundação & Década de 1980 & \multirow{5}{*}{$\sum_{u}^{N}$} & Fundação & Década de 1970 \\
\hline & O que fornece & Rótulos para Garrafas Plásticas & & O que fornece & $\begin{array}{l}\text { Insumos químicos para } \\
\text { produção de bebidas }\end{array}$ \\
\hline & Funcionários ( $\approx)$ & 280 & & Funcionários ( $\approx)$ & 2000 \\
\hline & $\begin{array}{c}\text { Localização (ma- } \\
\text { triz) }\end{array}$ & Região sul & & $\begin{array}{l}\text { Localização (ma- } \\
\text { triz) }\end{array}$ & Região centro-oeste \\
\hline & Fat. Br./ano $(\approx)$ & $\mathrm{R} \$ 50$ milhões & & Fat. Br./ano ( $\approx)$ & $\mathrm{R} \$ 80$ milhões \\
\hline
\end{tabular}

Figura 6 - Díades investigadas

\begin{tabular}{|c|c|c|c|}
\hline Díade & Empresa & \begin{tabular}{|r|} 
Cargo dos entrevistado \\
\end{tabular} & Idade \\
\hline \multirow{6}{*}{ 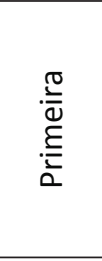 } & \multirow{4}{*}{$\mathrm{EF}$} & Gerente de Suprimentos & 25 \\
\hline & & Comprador de Matérias-Primas & 35 \\
\hline & & Comprador de Materiais de Despesa & 22 \\
\hline & & Coordenador de Almoxarifado & 40 \\
\hline & \multirow{2}{*}{ ET } & Gerente Geral de Filial & 50 \\
\hline & & Assistente Operacional & 45 \\
\hline \multirow{6}{*}{ 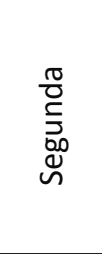 } & \multirow{3}{*}{$\mathrm{EF}$} & Gerente de Suprimentos & 25 \\
\hline & & Comprador de Matérias-Primas & 35 \\
\hline & & Gerente do Controle de Qualidade & 33 \\
\hline & GF1/AF & Comprador de Matérias-Primas & 28 \\
\hline & GF2 & Compradora de Matérias-Primas & 33 \\
\hline & FMP1 & Gerente Comercial Regional & 47 \\
\hline \multirow{3}{*}{ 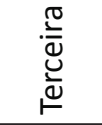 } & \multirow{3}{*}{$\mathrm{EF}$} & Gerente de Suprimentos & 25 \\
\hline & & Comprador de Matérias-Primas & 35 \\
\hline & & Gerente do Controle de Qualidade & 33 \\
\hline
\end{tabular}


O instrumento de coleta de dados da pesquisa foi desenvolvido com base no framework de pesquisa e nos trabalhos de Das e Teng (2001) e Barney e Hansen (1994): um questionário com 12 questões abertas, relacionadas aos constructos da confiança, do controle e do risco e ao impacto destes sobre as ações relacionais analisadas. As entrevistas foram realizadas na sede de cada empresa, gravadas e posteriormente transcritas para análise. Como auxílio à análise dos dados obtidos por meio da aplicação dos instrumentos de coleta de dados, construiu-se uma matriz de agrupamento conceitual em que as entrevistas foram organizadas em categorias que possuem relacionamento com os constructos e as variáveis da presente pesquisa, tendo-se como unidade de análise as díades da Figura 6.

\begin{tabular}{|c|c|}
\hline Díade & Contextualização \\
\hline $\begin{array}{c}1 \underline{a} \\
\text { Díade }\end{array}$ & $\begin{array}{l}\text { A ET é responsável pelo transporte de várias matérias-primas, insumos produtivos e embalagens } \\
\text { utilizadas pela EF. Essa empresa mantém relação de fornecimento de serviços com a EF há várias } \\
\text { décadas (os dados disponíveis não permitiram precisar o momento do início da relação). A EF é } \\
\text { atendida principalmente pela filial da ET localizada na mesma cidade. Do faturamento bruto da ET } \\
\text { (da unidade localizada na mesma cidade da EF), 3,5\% advêm da EF, seu maior cliente. Em } 2008 \text {, } \\
\text { em torno de 35\% do total gasto com fretes contratados pela EF foi despendido com esta ET. Não } \\
\text { existe contrato de prestação de serviço mantido entre ambas as empresas. As negociações são, } \\
\text { na grande maioria, travadas por via telefônica. Para a maioria dos serviços de frete contratados, } \\
\text { não é feita cotação com outras empresas transportadoras; isso ocorre apenas nos casos de ne- } \\
\text { cessidade de transporte de ativos de maior valor - este valor não é formalmente determinado. }\end{array}$ \\
\hline $\begin{array}{c}2 \underline{a} \\
\text { Díade }\end{array}$ & $\begin{array}{l}\text { O FMP1 e a EF iniciaram seu relacionamento em 2001, aumentando o volume e a frequência } \\
\text { das transações comerciais a partir de } 2004 \text {. Atualmente, o FMP1 fornece } 24 \text { rótulos à EF, o que } \\
\text { totaliza } 2 \% \text { do faturamento total do fornecedor de rótulos. Atualmente, a EF adquire } 90 \% \text { do seu } \\
\text { montante total de rótulos desta empresa; os outros } 10 \% \text { são adquiridos de outro fornecedor bra- } \\
\text { sileiro. Ainda em } 2008 \text {, o fornecimento era todo alocado no FMP1; entretanto, com a intervenção } \\
\text { da AF, houve uma redistribuição de volumes. O GF1/AF e o GF2 não cederam suas informações } \\
\text { de volume e participação de compra de rótulos desta empresa. Limitaram-se a informar que seu } \\
\text { relacionamento com o FMP1 iniciou, respectivamente, há sete e há quatro anos e que este for- } \\
\text { necedor tem a maior participação nas suas compras de rótulos. Informaram, ainda, que, com o } \\
\text { início do comitê de negociação de rótulos, também houve redistribuição de volumes. A criação } \\
\text { do comitê de rótulos consistiu em um evento importante para a díade, visto que transferiu dos } \\
\text { GFs para si a atribuição de selecionar os fornecedores de rótulos e decidir quais deles forneceriam } \\
\text { cada item de venda para todos os GFs. Por fim, nem antes da criação do referido comitê nem } \\
\text { depois, foi evidenciada a existência de contrato formalizando o fornecimento de rótulos do FMP1 } \\
\text { para os grupos fabricantes (incluindo a EF). Por outro lado, o inverso não é verdadeiro, visto que } \\
\text { este fornecedor de rótulos está submetido a todo o arcabouço de exigências do SGl }{ }^{2} \text {. }\end{array}$ \\
\hline $\begin{array}{c}3^{3 a} \\
\text { Díade }\end{array}$ & $\begin{array}{l}\text { A análise de todo o período histórico de fornecimento (1997-2008) mostra que, desde as primeiras } \\
\text { compras até } 2006 \text {, as transações efetuadas entre as duas empresas eram bastante esporádicas. Em } \\
2006, \text { o perfil da transação muda consideravelmente. Essa alteração de consumo ocorreu em fun- } \\
\text { ção da negociação de um contrato de fornecimento, firmado naquele ano e em vigor até a presente } \\
\text { data. Tal contrato prevê a aquisição de todos os insumos químicos utilizados na sanitização e lubri- } \\
\text { ficação das linhas de envase do FMP2, os quais são usados no processo produtivo por parte da EF } \\
\text { (são quinze os produtos adquiridos regularmente). O contrato em questão (cinco anos de vigência) } \\
\text { prevê a exclusividade de aquisição desses produtos dentro de uma política de precificação estável, } \\
\text { com um mecanismo de reajuste anual de preços. O contrato estipula um valor fixo a ser pago pela } \\
\text { EF por cada caixa de bebida produzida, independente da quantidade de químicos utilizados ou des- } \\
\text { perdiçados no processo produtivo. O contrato também responsabiliza o FMP2 pela concessão, pela } \\
\text { instalação, pela manutenção e pelo funcionamento adequado de todos os equipamentos necessá- } \\
\text { rios à aplicação de seus produtos fornecidos, sem custos adicionais, e exige a presença (8 horas/dia) } \\
\text { de um técnico do FMP2 em todos os dias úteis em que houver produção na fábrica. O contrato ainda } \\
\text { prevê uma série de exigências técnico-operacionais em relação ao FMP2, quase todas elas presen- } \\
\text { tes no SGI da casa matriz da EF, visto que este é um fornecedor homologado e monitorado pela } \\
\text { mesma. As sanções para o descumprimento dessas normativas são severas, incluindo desde multas } \\
\text { financeiras e rompimento do contrato com a EF até o possível rompimento do fornecimento com } \\
\text { todos os grupos fabricantes vinculado à casa matriz. Através desse contrato, a EF despende um total } \\
\text { financeiro que representa em torno de } 5 \% \text { do faturamento total da divisão de alimentos e bebidas } \\
\text { do FMP2, o qual também mantém fornecimento regular - através do mesmo sistema contratual - } \\
\text { com vários outros grupos fabricantes no Brasil e no exterior. }\end{array}$ \\
\hline
\end{tabular}

Figura 8 - Contextualização das díades analisadas 
Além das quinze entrevistas efetuadas, foi também realizada a análise dos principais documentos produzidos pela relação. Buscou-se, nesta fase, a coleta e observação de documentos gerados por meio dos relacionamentos interorganizacionais, como, por exemplo, contratos, pedidos de compra, atas de reunião, controles formalizados e assim por diante, a fim de coletar informações adicionais às entrevistas e melhor compor o panorama de pesquisa relativo ao estabelecimento e impacto mútuo dos três constructos citados anteriormente.

Os dados foram analisados qualitativamente, por meio da matriz de agrupamento conceitual citada. Além disto, as entrevistas foram examinadas pela técnica da análise de conteúdo, que objetiva fazer a conexão entre a teoria prévia levantada na revisão de literatura e o que na prática foi encontrado durante a coleta de dados (BARDIN, 1977). As limitações desta pesquisa são aquelas inerentes aos estudos de caso (YIN, 2004).

\section{RESULTADOS DA PESQUISA}

Os resultados estão organizados da seguinte forma: primeiramente, são mostrados os resultados da análise sobre os relacionamentos de cada díade no que tange às inter-relações existentes entre confiança, controle e risco. Embora o detalhamento dos resultados traga as perspectivas dos dois lados da díade (com exceção da terceira díade, que mostra apenas a perspectiva da EF), cada díade será resumida por meio da figura que mostra a visão relacional a partir da EF, visto que as análises efetuadas no outro lado das díades (com os fornecedores da EF) visaram complementar o ponto de vista da EF. No último tópico dos resultados, são apresentadas as principais proposições de pesquisa geradas a partir da análise dos resultados conjuntos das díades pesquisadas.

\subsection{Primeira díade: EF $\leftrightarrow$ ET}

As Figuras 9 e 10 resumem as influências ocorridas entre os diversos tipos de confiança, controles e riscos na relação estabelecida entre EF e ET. A leitura da Figura 9, assim como das figuras seguintes, pode ser feita com base nas setas (direção e cor). A direção da seta apresenta o sentido de influência da variável, enquanto que sua cor mostra o tipo de força influenciadora: potencializadora/cor vermelha; ou diminuidora/cor preta. Já o tipo de linha mostra se a influência é positiva ou negativa para a relação com um todo: linha contínua/influência positiva para a relação (aumento de confiança e diminuição de riscos); linha tracejada/influência negativa para a relação (diminuição da confiança e aumento de riscos). Cada tipo de confiança, risco e controle alocados dentro das caixas do desenho - é seguido dos principais elementos que os preenchem (o desenho aponta apenas as variáveis evidenciadas nas análises). 


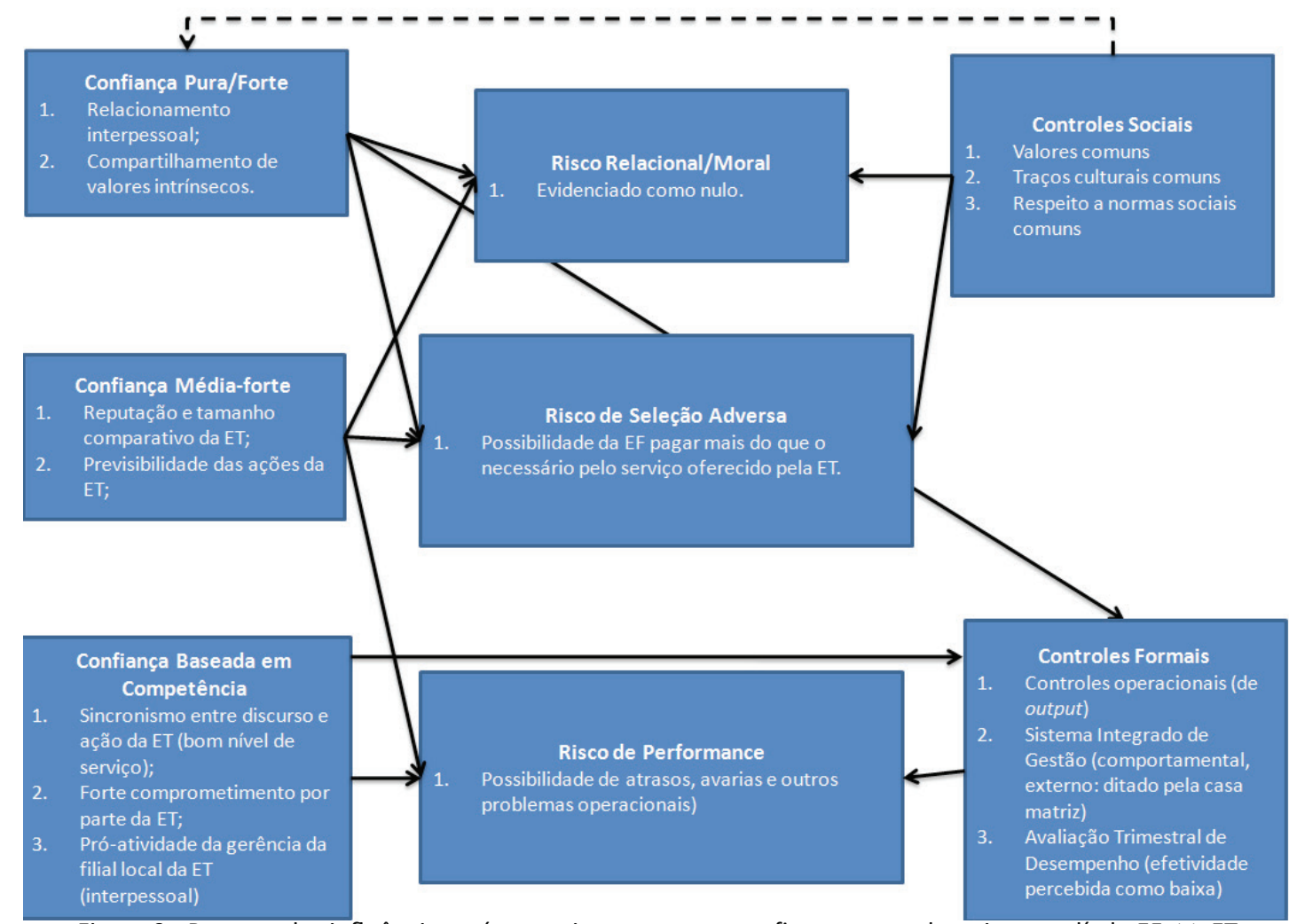

Figura 9 - Resumo das influências mútuas existentes entre confiança, controle e risco na díade EF $\leftrightarrow$ ET

As evidências da EF sustentam um quadro geral de confiança em relação à ET. A existência dos três tipos de confiança foi verificada como elemento determinante para a duração e qualidade da relação entre ambas as empresas. A confiança forte/pura aparece como a mais representativa, e o relacionamento interpessoal, juntamente com o compartilhamento de valores comuns, surge como o principal motivador desse tipo específico de confiança. Em vários momentos, os colaboradores da EF expressam sua confiança na competência e nas intenções do gerente geral da $\mathrm{ET}$, assim como a existência de uma visão comum em relação ao que é desejável em termos de comportamento negocial. Essa visão diferenciada em relação ao profissional da ET também indicou uma assimetria de confiança em relação às outras filiais da ET.

A presença da confiança forte/pura refletiu a inexistência de sinais de riscos relacionais/ morais - e, ao mesmo tempo, a diminuição de intensidade do risco de seleção adversa - nas entrevistas realizadas. A existência da confiança forte/pura e da confiança baseada em competência, somada à ausência de riscos relacionais/morais percebidos, evidenciou a diminuição da intensidade de controles formais, que foram documentalmente evidenciados como não intensivos: observou-se que os mecanismos de controle se resumem aos aspectos operacionais essenciais, mesmo existindo certa percepção de risco de seleção adversa e performance. 


\begin{tabular}{|c|c|c|c|}
\hline Díade & & Principais pontos & Nível \\
\hline \multirow{9}{*}{$\mid \begin{array}{l}\boldsymbol{E F} \\
\mathbf{y}_{---}\end{array}$} & \multirow{3}{*}{ 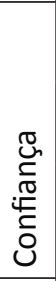 } & $\begin{array}{l}\text { A existência de fortes traços de confiança forte/pura tem influ- } \\
\text { ência determinante sobre todo o quadro relacional. }\end{array}$ & \multirow{3}{*}{ Alto } \\
\hline & & $\begin{array}{l}\text { Foi constatada a ênfase em relacionamentos interpessoais de } \\
\text { confiança. }\end{array}$ & \\
\hline & & $\begin{array}{l}\text { Os elementos existentes de confiança média-forte, como tem- } \\
\text { po de relacionamento, reputação, marca e porte das empresas, } \\
\text { cumprem papel relevante no quadro de relações. }\end{array}$ & \\
\hline & & $\begin{array}{l}\text { Os riscos percebidos por parte da EF são creditados pela mesma } \\
\text { principalmente às suas próprias lacunas internas de gestão. }\end{array}$ & \multirow{3}{*}{ Baixo } \\
\hline & & $\begin{array}{l}\text { Os riscos percebidos como mais relevantes, por parte da ET, são } \\
\text { diferentes daqueles percebidos pela EF. A causa mais provável é } \\
\text { a posição ocupada na díade por ambas as empresas. }\end{array}$ & \\
\hline & 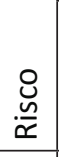 & $\begin{array}{l}\text { A filial local da ET é percebida de modo bastante diverso pela EF } \\
\text { em relação a suas outras unidades, denotando a importância da } \\
\text { frequência de interações vis-à-vis e da proximidade físico-psico- } \\
\text { lógica entre as organizações da díade. }\end{array}$ & \\
\hline & \multirow{3}{*}{$\begin{array}{l}\frac{0}{0} \\
\text { 논 } \\
\text { c } \\
0\end{array}$} & $\begin{array}{l}\text { As evidências mostraram haver ênfase nos controles informais } \\
\text { e em relações mais informais, em geral, por ambas as empresas } \\
\text { da díade. }\end{array}$ & \multirow{3}{*}{$\begin{array}{l}\text { Ênfase em } \\
\text { controles } \\
\text { informais }\end{array}$} \\
\hline & & $\begin{array}{l}\text { Embora a ET perceba a existência de risco de performance em } \\
\text { relação à EF, não foram impostos controles adicionais sobre a } \\
\text { mesma, provavelmente devido à assimetria de poder presente } \\
\text { na relação de fornecimento. }\end{array}$ & \\
\hline & & $\begin{array}{l}\text { A existência de fortes traços de confiança forte/pura tem influ- } \\
\text { ência determinante sobre todo o quadro relacional. }\end{array}$ & \\
\hline
\end{tabular}

Figura 10 - Resumo dos resultados da díade $\mathrm{EF} \leftrightarrow \mathrm{ET}$

A reputação da ET - tendo em vista seu porte e o tempo de mercado - e a previsibilidade de suas ações - gerada pelo longo período de prestação de serviços sem falhas maiores - foram observadas como os fatores-chave de outro tipo de confiança: a média-forte. A confiança baseada em competência, por sua vez, também se mostrou fortemente presente. A exemplo da confiança forte/pura, esse tipo de confiança também existe em relação à atuação de gerente geral da ET, visto como altamente competente, comprometido e proativo em relação às necessidades da EF.

A análise do conjunto de entrevistas e documentos verificados na $\mathrm{ET}$, em relação à $\mathrm{EF}$, mostrou um quadro geral semelhante ao anteriormente apresentado, principalmente, no que diz respeito à existência e relevância da confiança forte/pura (também fortemente baseada nos relacionamentos interpessoais e na percepção de existência de valores comuns) e à inexistência de riscos relacionais/morais.

As principais diferenças nas análises da $\mathrm{ET}$, em relação à $\mathrm{EF}$, foram verificadas na percepção dos riscos e na dinâmica dos controles. Enquanto que a EF evidenciou uma percepção geral dos riscos baixa (embora existente em certa medida), a ET mostrou certa preocupação com o risco de investimentos específicos que a EF lhe imputa, visto ser este seu maior cliente, o qual exige uma série de serviços personalizados. Além disso, a configuração dos competidores da ET indica a existência de várias outras transportadoras que oferecem serviços similares a preços bastante inferiores aos praticados pela mesma.

Além desse risco, há também a percepção de existência de riscos de performance, materializados em pedidos emergenciais, mudanças imprevistas e outros descompassos operacionais eventuais observados pela ET na operação da EF. Entretanto, ao contrário do que a literatura prevê (a instauração de controles formais frente a esse risco), não houve por parte da ET a criação de controles adicionais para enfrentá-lo. 


\subsection{Segunda díade: EF, GF1/AF, GF2 $\leftrightarrow$ FMP1}

As Figuras 11 e 12 resumem as dinâmicas verificadas entre confiança, controle e risco nas relações estabelecidas entre EF, GF1/AF, GF2 e FMP1. A exemplo da primeira díade, neste caso, também se verifica que a confiança forte/pura existente reduz concomitantemente o risco relacional/moral e o risco de seleção adversa. Destaca-se a ênfase dada pela EF ao papel do gerente comercial do FMP1 como potencializador desse tipo de confiança (relacionamento interpessoal). Ambos os riscos também recebem influência dos controles sociais existentes.

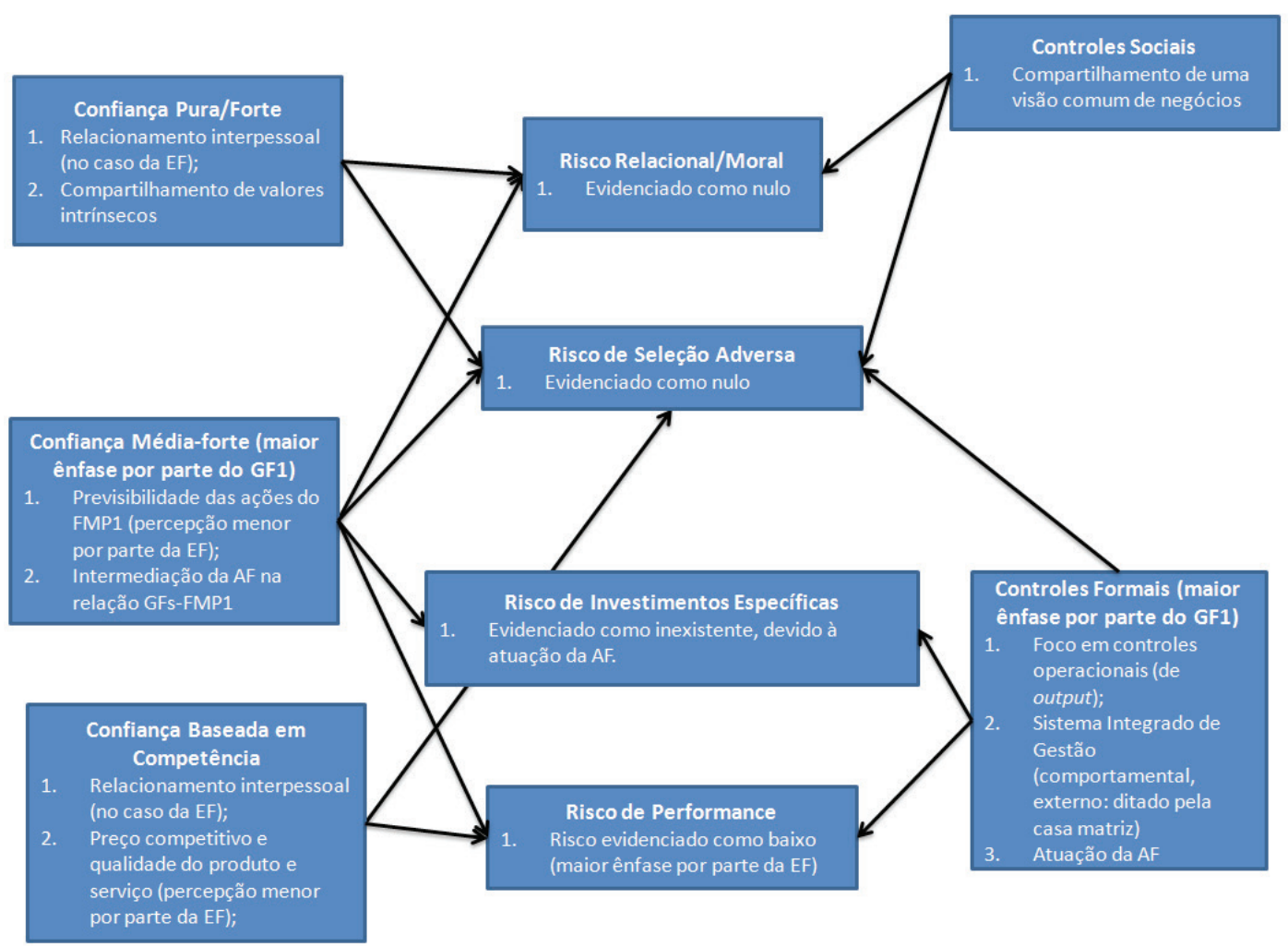

Figura 11 - Resumo das influências mútuas existentes entre confiança, controle e risco na díade EF, GF1/AF, GF2 ↔ FMP1

A confiança média-forte tem papel relevante no quadro relacional em questão, afetando (diminuindo) todos os quatro riscos analisados. Um ponto de destaque, nesse sentido, é a atuação de um agente externo (casa matriz e AF - devido ao seu poder de barganha e à sua influência geral sobre a relação) como forte potencializador desse tipo de confiança. A confiança baseada em competência é evidenciada por meio do bom desempenho operacional (serviço, produto e preço) do FMP1. Novamente, a EF põe em evidência o gerente comercial do fornecedor de rótulos, ao indicá-lo como um dos principais responsáveis pela confiança baseada em competência imputada ao FMP1.

Os maiores controles formais são externos à relação, embora haja controles sistematizados pelos GFs operando na relação com o FMP1. Esses dispositivos externos são os impostos pela casa matriz. Em conjunto com os controles dos GFs, tais mecanismos influenciam os riscos de seleção adversa, de performance e de investimentos específicos.

Dessa forma, o único risco percebido como realmente relevante pela EF - esse risco não foi interpretado como relevante pelos outros grupos fabricantes - é a atuação da AF, que, confor- 
me as evidências mostraram, embora tenha aumentado os controles e as seguranças em relação aos fornecedores, diminuiu consistentemente a sua autonomia.

Quando analisadas as entrevistas e a documentação do FMP1, também é verificada a existência de confiança forte-pura e ênfase em relações interpessoais informais. Já a análise das outras variáveis traz algumas evidências que diferenciam o ponto de vista do FMP1 do ponto de vista de seus clientes, mencionado anteriormente.

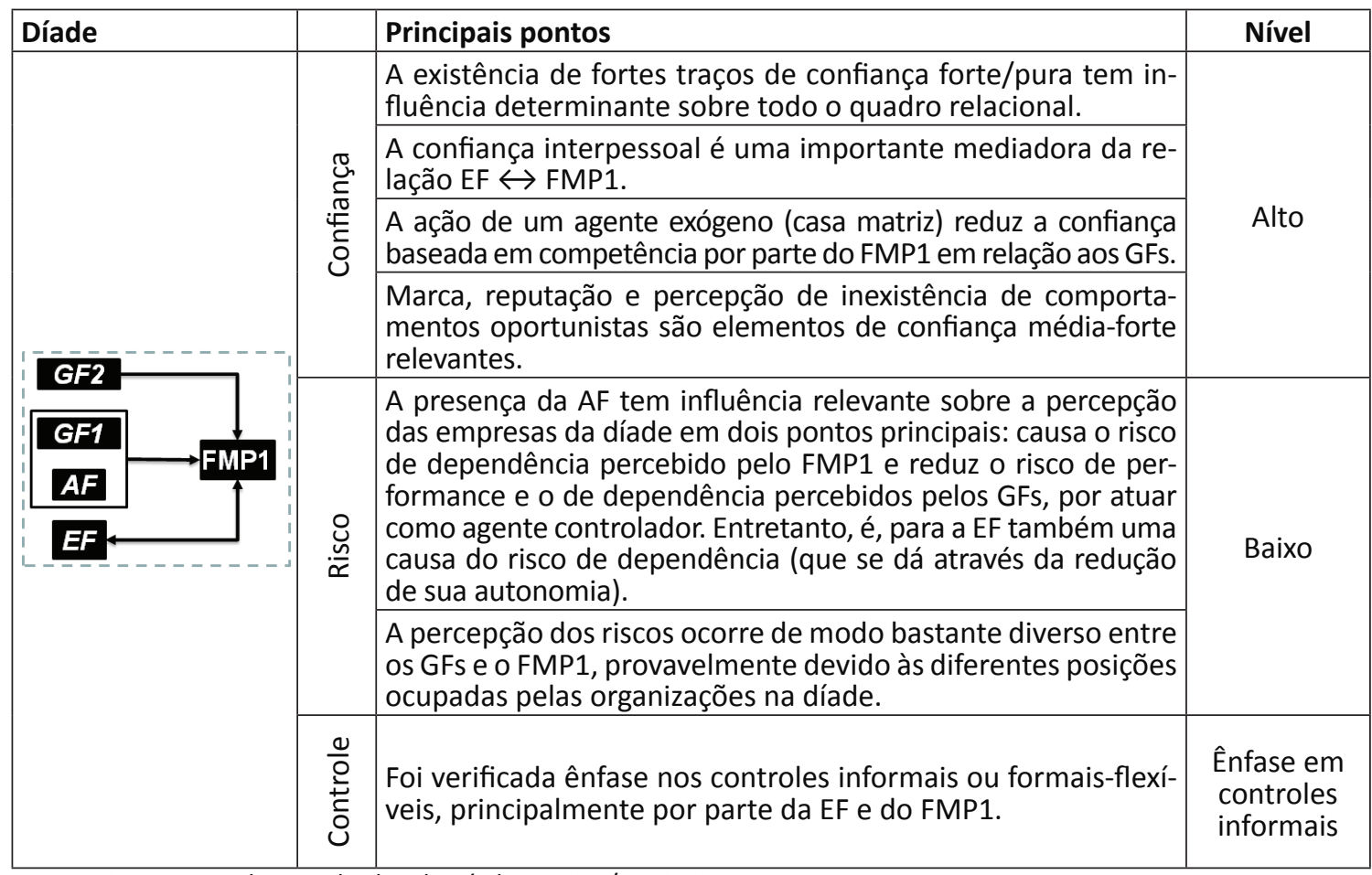

Figura 12 - Resumo dos resultados da Díade EF, GF1/AF, GF2 $\leftrightarrow$ FMP1

Para o FMP1, o risco de dependência percebido (investimentos específicos) é diretamente causado por um fator externo (AF) e é entendido como relativamente alto em decorrência de não haver dispositivos contratuais em ação que objetivem a diminuição desse risco. Essa lógica justifica a decisão do FMP1 em começar a transferir parte de seus esforços a mercados outros que não apenas os GFs - estes dependem das decisões da AF. A incapacidade de impor esses controles origina-se na própria estrutura de relação e assimetria de poder existente entre as organizações envolvidas. $O$ risco de performance também tem sua percepção elevada devido: (a) à baixa confiança baseada em competência em relação à EF e (b) aos controles formais operacionais (de output) sistematizados embora existentes - não serem suficientes para dar maior previsibilidade às ações da EF.

Dessa forma, os pontos de destaque nessa matriz de relacionamentos (Figura 11) são: (a) o desequilíbrio causado por um agente externo à relação (a AF), que acaba imprimindo uma dinâmica diferente ao padrão de relações possíveis entre as empresas analisadas; e (b) a ênfase constatada nos relacionamentos interpessoais. 


\subsection{Terceira díade: $\mathrm{EF} \rightarrow \mathrm{FMP2}^{6}$}

As análises efetuadas sobre os resultados obtidos na relação estabelecida entre EF e FMP2 compuseram um cenário bastante diverso das duas díades apresentadas anteriormente, conforme se observa nas Figuras 13 e 14. A principal diferença consiste na ausência de confiança forte/pura por parte da EF. A causa dessa falta de confiança moral é o reflexo de uma série de eventos ocorridos desde o cancelamento do contrato de fornecimento entre as duas partes.

A ausência da confiança forte/pura, somada a uma baixa confiança baseada em competência, fez com que todos os tipos de riscos analisados (riscos relacional/moral, de seleção adversa e de investimentos específicos) fossem percebidos como existentes e preocupantes pela EF. De fato, a análise dos resultados mostrou que essa relação se retroalimenta: os riscos são a causa de falta de confiança e vice-versa. Como agravante, os respondentes da EF mencionaram não crer no compartilhamento profundo da mesma visão de negócio e dos mesmos princípios do FMP2, o que implica a ausência de controles sociais sobre a relação.

Dessa configuração resulta a intensificação dos controles formais (que refletem o único tipo de confiança existente na relação: a média-forte) por parte da EF sobre o FMP2. A análise documental mostrou haver onze mecanismos formais de controle instituídos pela EF, que incluem a existência de dois contratos (contrato de aquisição e contrato de prestação de serviço), o controle do cartão ponto do técnico do FMP2 que monitora e ajusta o desempenho dos produtos em linha de produção e a exigência de entrega de laudos e relatórios semanais de análise de produtividade e verificações de horários automatizadas da utilização dos insumos químicos.

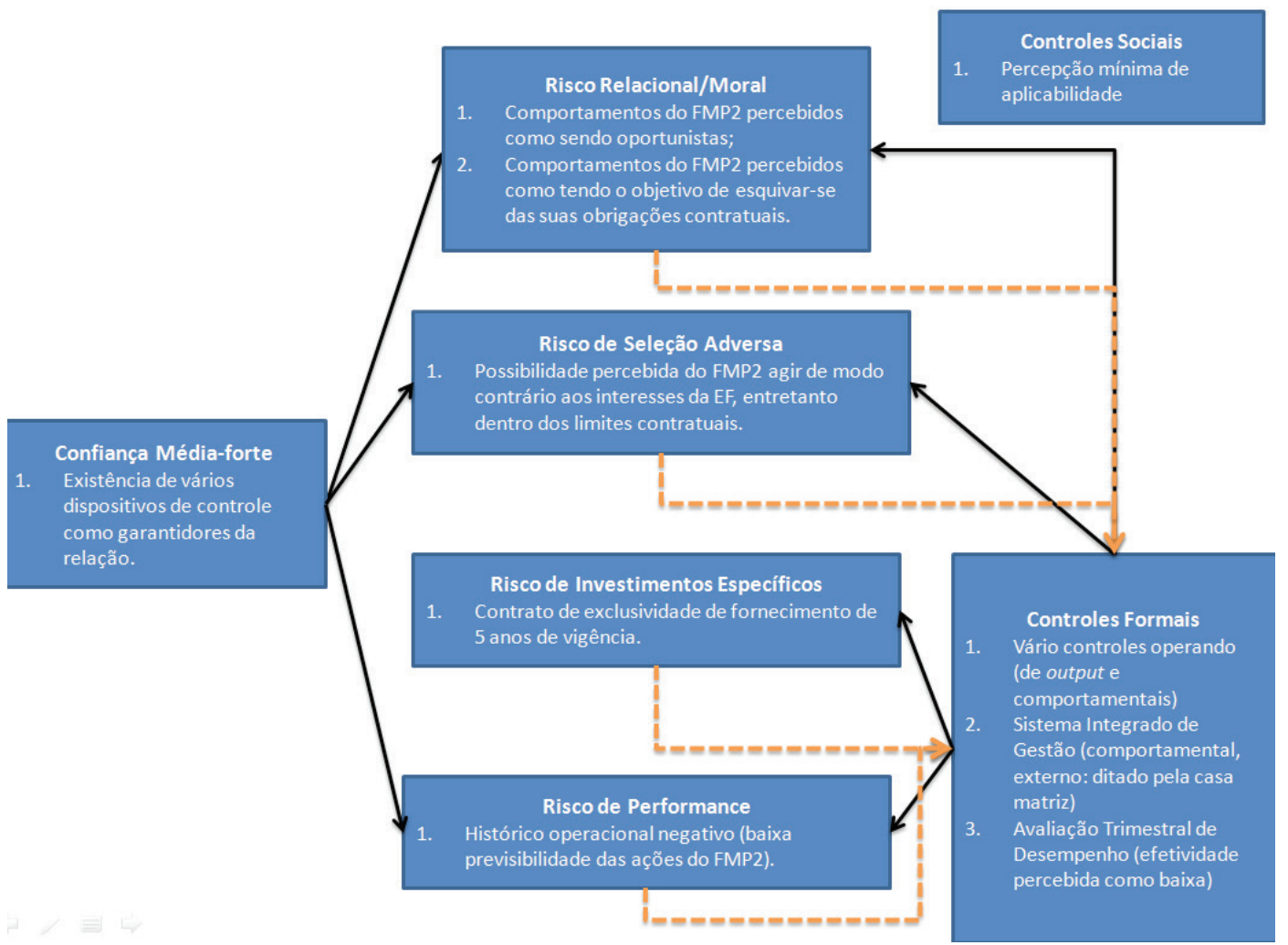

Figura 13 - Resumo das influências mútuas existentes entre confiança, controle e risco na díade EF $\rightarrow$ FMP2

6 Essa díade foi analisada apenas a partir da perspectiva da EF: a FMP2 não autorizou a publicação de suas informações fora do âmbito negocial estabelecido entre sua empresa e a EF. 


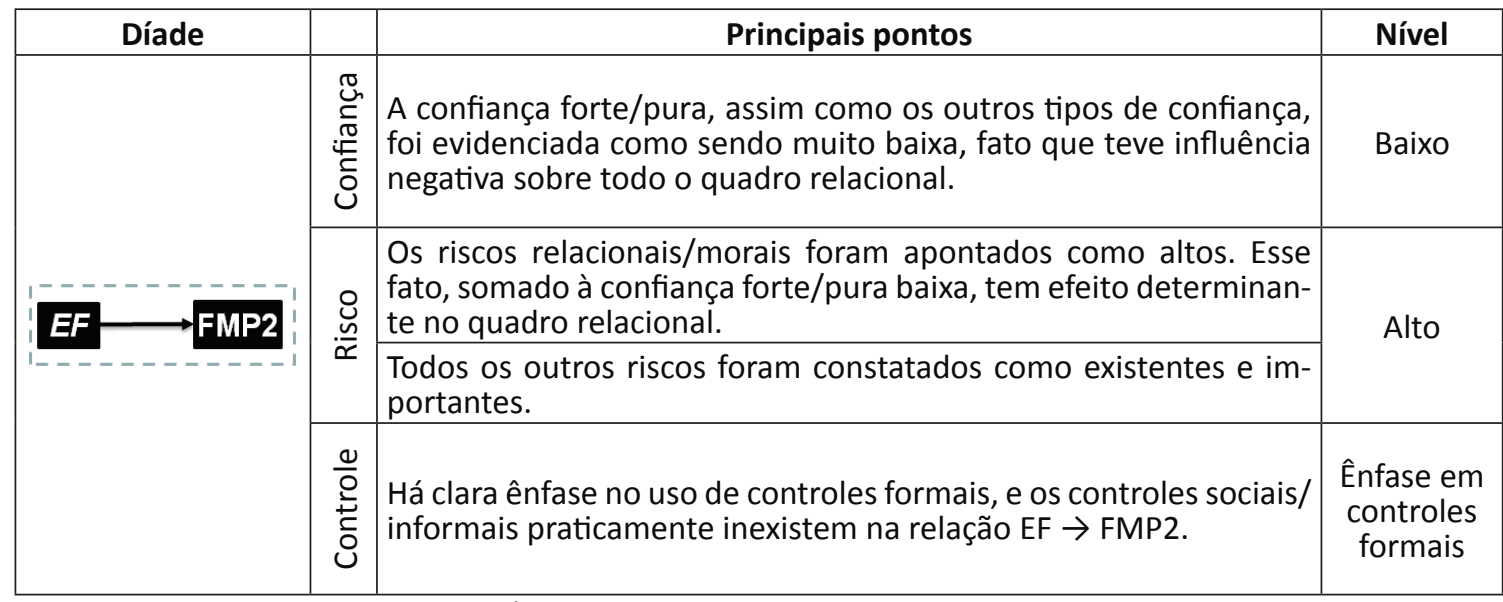

Figura 14 - Resumo dos resultados da díade EF $\rightarrow$ FMP2

Mesmo assim, as análises mostraram que a pressão exercida pela confiança média-forte e por esses controles formais não foram suficientes para reduzir a níveis moderados os riscos relacionais percebidos como existentes, ao contrário do que sustenta Das e Teng (2001). Tal constatação traz à tona a questão do desequilíbrio de forças dos constructos e das variáveis que estão em relação, questão esta que a teoria mainstream da temática não aborda.

Do conjunto das análises realizadas sobre as três díades, surgem oito principais proposições referentes às influências mútuas verificadas entre confiança, controles e riscos, as quais são expostas na Figura 15, a seguir.

\begin{tabular}{|c|c|c|}
\hline \multicolumn{2}{|r|}{ Proposições } & \multirow[b]{2}{*}{\begin{tabular}{|l} 
Detalhamento \\
Quando existe a confiança forte/pura, há a tendência de haver uma \\
maior tolerância em relação aos riscos percebidos pelos responden- \\
tes. Riscos percebidos como reais e atuantes e como não tendo rela- \\
ção direta com a confiança forte/pura tendem a ser alvos de um vo- \\
lume e uma intensidade menores de controles formais quando esse \\
tipo de confiança é percebido como forte. O mesmo ocorre com o \\
risco relacional/moral: na única relação em que esse risco foi perce- \\
bido como existente (EF $\rightarrow$ FMP2), todos os dispositivos de confiança \\
e controles formais existentes não foram suficientes para reduzir os \\
riscos percebidos a níveis entendidos como suficientemente seguros.
\end{tabular}} \\
\hline 1 & $\begin{array}{l}\text { Confiança forte/pura - quando } \\
\text { existente ou quando ausente - } \\
\text { e risco relacional/moral - quan- } \\
\text { do existente - sobressaem-se } \\
\text { às outras variáveis e aos cons- } \\
\text { tructos inclusos no modelo de } \\
\text { análise e influenciam as rela- } \\
\text { ções estabelecidas na díade de } \\
\text { modo determinante }\end{array}$ & \\
\hline 2 & $\begin{array}{l}\text { A confiança interpessoal - } \\
\text { quando existente - gera influ- } \\
\text { ências relevantes nas relações } \\
\text { estabelecidas nas díades }\end{array}$ & $\begin{array}{l}\text { Confiança interpessoal foi destacada em várias situações como sen- } \\
\text { do um ponto central e determinante das relações estabelecidas, por } \\
\text { vezes havendo transferência desse tipo de confiança a toda organiza- } \\
\text { ção na qual a pessoa confiada trabalha. }\end{array}$ \\
\hline 3 & $\begin{array}{l}\text { A eficácia dos controles na re- } \\
\text { dução dos riscos percebidos é } \\
\text { mediada pelo nível de confian- } \\
\text { ça forte/pura existente }\end{array}$ & $\begin{array}{l}\text { A eficácia dos controles na redução dos riscos percebidos pelos en- } \\
\text { trevistados mostrou-se, de certa forma, mediada pelos tipos de con- } \\
\text { fiança existentes, mais especificamente pela confiança pura/forte, } \\
\text { considerando a intensidade de influência desta variável nos quadros } \\
\text { relacionais analisados. }\end{array}$ \\
\hline 4 & $\begin{array}{l}\text { A posição das organizações em } \\
\text { uma díade e sua assimetria de } \\
\text { poder são determinantes na } \\
\text { definição e implementação dos } \\
\text { controles comuns às empresas } \\
\text { que a formam }\end{array}$ & $\begin{array}{l}\text { A definição e a imposição dos controles relacionais condicionam-se à } \\
\text { estrutura das relações estabelecidas entre as organizações (fornece- } \\
\text { dor e cliente, por exemplo) e às suas relações de poder. }\end{array}$ \\
\hline 5 & $\begin{array}{l}\text { As relações internas das díades } \\
\text { podem ser influenciadas por fa- } \\
\text { tores externos: outras organiza- } \\
\text { ções e fatores institucionais }\end{array}$ & $\begin{array}{l}\text { Os resultados mostraram que a AF e a casa matriz exercem influ- } \\
\text { ências fundamentais sobre as percepções das empresas formadoras } \\
\text { das díades analisadas, diminuindo ou aumentando os diversos níveis } \\
\text { de confiança, controle e risco existentes e, dessa forma, alterando as } \\
\text { ações e políticas definidas pelas organizações. }\end{array}$ \\
\hline
\end{tabular}




\begin{tabular}{|l|l|l|}
\hline \multicolumn{2}{|c|}{ Proposições } & \multicolumn{1}{c|}{ Detalhamento } \\
\hline $\mathbf{6}$ & $\begin{array}{l}\text { Relações estabelecidas entre } \\
\text { confiança, controle e risco são } \\
\text { contingenciais }\end{array}$ & $\begin{array}{l}\text { As análises mostraram que as interinfluências estabelecidas entre } \\
\text { confiança, controle e risco não obedecem a um único padrão relacio- } \\
\text { nal. Se uma variável for alterada ao longo da história relacional entre } \\
\text { as empresas, seu quadro relacional como um todo sofre mudanças. }\end{array}$ \\
\hline $\mathbf{7}$ & $\begin{array}{l}\text { As variáveis exercem diferen- } \\
\text { tes intensidades de influência } \\
\text { umas sobre as outras }\end{array}$ & $\begin{array}{l}\text { A exemplo da confiança forte/pura e do risco relacional/moral, ob- } \\
\text { serva-se que as outras variáveis também exercem diferentes inten- } \\
\text { sidades de influência, seja devido à natureza de seus elementos for- } \\
\text { madores, seja devido ao modo como elas se inter-relacionam com as } \\
\text { outras variáveis pesquisadas. }\end{array}$ \\
\hline $\mathbf{8}$ & $\begin{array}{l}\text { Os elementos formadores de } \\
\text { uma variável podem ter diver- } \\
\text { sas naturezas e funções }\end{array}$ & $\begin{array}{l}\text { Uma mesma variável pode ser constituída por elementos de diferen- } \\
\text { tes funções específicas ou mesmo de diversas naturezas, que trazem, } \\
\text { por sua vez, diferentes desdobramentos nas díades analisadas. }\end{array}$ \\
\hline
\end{tabular}

Figura 15 - Proposições geradas a partir da análise conjunta dos resultados da pesquisa

Essas proposições resumem os achados mais relevantes deste estudo. Devido ao fato de ser este um estudo exploratório, novas pesquisas são demandadas para creditar-lhes validade externa.

\section{CONSIDERAÇÕES FINAIS}

O presente estudo buscou avançar na compreensão das inter-relações influenciais ocorridas entre a confiança, o risco e o controle no âmbito das cadeias de suprimentos. Assim, por meio, inicialmente, do incremento e, após, da aplicação do framework teórico de Das e Teng (2001), operacionalizado através de investigação de natureza qualitativa, foi possível responder a pergunta de pesquisa deste trabalho.

Esses procedimentos também levaram às seguintes conclusões gerais: (1) as relações estabelecidas entre confiança, controle e risco são contingenciais (não houve regularidade geral observada); (2) a análise global dos constructos e das variáveis, em cada díade, oferece uma capacidade de compreensão contextual maior do que as análises individuais; (3) as variáveis pesquisadas exercem diferentes intensidades de influência em todas as relações - tais diferenças de força, por vezes, afetam todo o equilíbrio da matriz de relações, às vezes a ponto de anular outras forças contextuais, de modo que autores como Das e Teng (2001), dentre outros, não preveem diferentes níveis de força para cada uma das suas variáveis de pesquisa -; (4) os elementos observados como formadores das variáveis de pesquisa (seus predecessores) não são sempre os mesmos, e, sendo diferentes, constatou-se que não agem sempre de forma a exercer os mesmos padrões de influência previstos por Das e Teng (2001); (5) o nível interpessoal, em alguns casos apresentados nos resultados desta pesquisa, teve relevância determinante como influenciador das outras variáveis do modelo, demonstrando interação direta com o nível interorganizacional, já que transfere e recebe influências perceptivas importantes; (6) a dinâmica do poder relacional e das estruturas interorganizacionais exerce influência sobre as relações estabelecidas entre confiança, controle e risco; (7) agentes externos às relações estabelecidas entre as organizações analisadas podem mudar o equilíbrio das mesmas, o que sugere a necessidade de considerar o contexto maior nas análises realizadas sobre quaisquer díades; (9) por fim, todas essas constatações permitem observar que os relacionamentos estabelecidos entre confiança, controles e riscos são complexos. Assim, devido à dinamicidade e complexidade dos atores e recursos envolvidos nas relações interorganizacionais, não há, até o momento, como traçar regras gerais para as dinâmicas existentes entre os três constructos analisados. Entretanto, com base nos resultados alcançados, entende-se que o framework de pesquisa oferece visões e tendências gerais que sinalizam caminhos válidos de análise. 
O surgimento dos novos elementos contextuais mencionados a partir dos resultados desta pesquisa - representados nas proposições teóricas listadas anteriormente -, evidenciados como influenciadores das inter-relações existentes entre confiança, controle e risco, consiste na principal contribuição acadêmica deste trabalho. Os resultados também mostram que, devido à complexidade dos fenômenos analisados, uma perspectiva linear de investigação não se faz suficiente para fazer frente às inter-relações mantidas entre esses três constructos. Adicionalmente, o presente trabalho contribui para o estudo do constructo da confiança no Brasil. Com exceção de alguns poucos trabalhos - por exemplo, Pirani e Cunha (2010), Cunha e Marlene (2004) e Cunha (2004) -, a confiança não tem recebido maior atenção da comunidade acadêmica no país.

As implicações gerenciais concentram-se na capacidade analítica que esta pesquisa oferece. Entende-se que o avanço no conhecimento dos novos elementos mencionados aumentará sua capacidade de análise, para, então, servir como base para a busca de evidências que suportem decisões estratégicas relacionadas à confiança, aos controles e aos riscos, como, por exemplo: definição do tipo e da extensão dos controles a serem negociados; sistematização da verificação dos riscos com maior potencial de dano ao negócio; e tomada de decisões com base na utilização ou não de elementos externos à relação como pontos de suporte a esta. Adicionalmente, acredita-se que a distância temporal do momento da coleta de dados não prejudica as conclusões e contribuições do presente estudo. Não há sinais de que nos últimos anos tenham ocorrido evoluções tecnológicas ou organizacionais disruptivas que pudessem mudar drasticamente os padrões relacionais observados neste estudo.

\section{REFERÊNCIAS}

BACHMANN, R. Trust, Power and control in trans-organizational relations. Technical University Hamburg. Artigo apresentado na SASE-Conference. Madison/Wiscosin, USA, July. 1999.

BARNEY, J. B., HANSEN, M. H. Trustworthiness as a Source of Competitive Advantage. Strategic Management Journal. vol. 15, p. 175-190, 1994.

BIJLSMA-FRANKEMA, K;COSTA,A.C.;Undertanding the Trust-Control Nexus. International Sociology, vol. 20, n.3, 259-282, 2005.

CUNHA, Cleverson Renan da. A confiança nas relações interoganizacionais cooperativas: Estudo múltiplo de casos em empresas de Biotecnologia no Brasil. Belo Horizonte, 2004. 283 f. Tese (Doutorado em Administração)Centro de Pós-Graduação e Pesquisa em dministração, Universidade Federal de Minas Gerais, Belo Horizonte, 2004.

CUNHA, C. R.; MARLENE, M. C. O. L. A confiança nas relações interorganizacionais. In: O\&S - Organizações e Sociedade, Salvador, v.11, Edição Especial, p. 79-93, 2004.

CUNHA, C. R.; PIRANI, S. L. A Formação da Confiança: um Estudo no Pool da UNIBRASPE. Revista de Administração da UFSM, vol. 3, n. 3, p. 375-392, 2010.

CHU, S. Y.; FANG, W. C. Exploring the Relationships of Trust and Commitment in Supply Chain Management. Journal of American Academy of Business, Cambridge, vol. 9, n. 1, p. 214-228, 2006.

DAS, T. K.; TENG, BS. Between Trust and Control: Developing Confidence in Partner Cooperation in Alliances. Academy of Management Review, vol. 23, p. 491-512, 1998.

DAS, T. K.; TENG, B. S. Trust, Control, and Risk in Strategic Alliances: an Integrated Framework. Organization Studies, vol. 22, n. 2, p. 251-283, 2001.

INKPEN, A. C.; CURRALL, S. C. The Coevolution of Trust, Control, and Learning in Joint Ventures. Organization Science, vol. 15, n. 5, 2004. 
MCEVILY, B., PERRONE, V., ZAHEER, A. Trust as an Organizing Principle. Organization Science, vol. 14, n. 1, p. 91-103 2003.

MÖLLERING, G.; The Trust/Control Duality. International Sociology, vol. 20, n. 3, 2005.

MORGAN, R. M.; HUNT, S. D. The CommitmentTrust Theory of Relationship Marketing. Journal of Marketing, vol. 58, n. 3, p. 283-305, 1994.

NEW, S. J. The Scope of Supply Chain Management Research. Supply Chain Management, vol. 2, n. 1, p. 15-22, 1997.

OUCHI, W. G.; MAGUIRE, M. A. Organizational Control: Two Functions. Administrative Science Quarterly, vol. 20, p. 559-569, 1975.

SAHAY, B. S. Understanding Trust in Supply Chain Management Relationships. Industrial Management \& Data Systems, v.103, n.8, p. 553-563, 2003

SIMON, H. A. Administrative Behavior. New York: Free Press. 1976.

SVENSSON, G. Perceived Trust Towards Suppliers and Customers in Supply Chains of the Swedish Automotive Industry. International Journal of Physical Distribution \& Logistics Management, vol. 31, n. 9, p. 647-662, 2001.

YIN, R. K. Estudo de Caso: Planejamentos e Métodos. 3a ed. São Paulo: Bookman, 2004. 